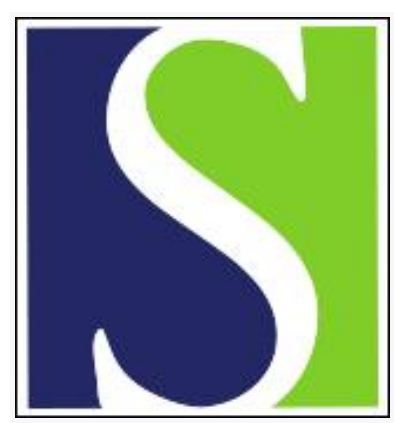

Scand J Work Environ Health 1987;13(1):47-51

https://doi.org/10.5271/sjweh.2087

Issue date: Feb 1987

Abnormalities of pulmonary function and pleural disease among titanium metal production workers.

by Garabrant DH, Fine LJ, Oliver C, Bernstein L, Peters JM

This article in PubMed: www.ncbi.nlm.nih.gov/pubmed/3495034

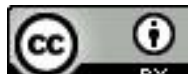




\title{
Abnormalities of pulmonary function and pleural disease among titanium metal production workers
}

\author{
by David H Garabrant, MD, ${ }^{1}$ Lawrence J Fine, MD, ${ }^{2}$ Christine Oliver, MD, ${ }^{3}$ Leslie Bernstein, PhD, ${ }^{1}$ \\ John M Peters, MD ${ }^{1}$
}

\begin{abstract}
GARABRANT DH, FINE LJ, OLIVER C, BERNSTEIN L, PETERS JM. Abnormalities of pulmonary function and pleural disease among titanium metal production workers. Scand $J$ Work Environ Health 13 (1987) $47-51$. The authors conducted a cross-sectional survey of respiratory disease among 209 titanium metal production workers. Work in areas where there was exposure to titanium tetrachloride and titanium dioxide particulates was associated with reductions in ventilatory capacity. Pleural disease (plaques and diffuse thickening) was present in the chest radiographs of $17 \%$ of the subjects and was associated with the duration of work in titanium manufacturing. It was also associated with past asbestos exposure. After control for asbestos exposure, it remained associated with titanium manufacturing. The findings are consistent with the hypothesis that titanium tetrachloride and titanium dioxide particulates may be associated with a reduction in ventilatory capacity and that the overall process of titanium manufacturing may be associated with unexpected pleural disease.
\end{abstract}

Key terms: industry, lung diseases, occupational diseases, pneumoconiosis, titanium.

Titanium metal is produced by the reduction of titanium tetrachloride with metallic sodium to yield a solid mixture of sodium chloride and titanium. This mixture is chipped into small pieces with pneumatic hammers, and the sodium chloride is removed by washing the pieces with hydrochloric acid, which leaves behind small lumps of high-purity titanium. Workers involved in the chipping and washing process are exposed to a mixed aerosol of titanium, sodium chloride, and hydrochloric acid, while workers involved in the reduction process are exposed to titanium tetrachloride vapor, titanium oxychloride $\left(\mathrm{TiOCl}_{2}\right)$, and titanium dioxide particulates. In addition workers in the reduction process may be exposed to welding fumes generated in the maintenance and repair of the reduction vessels.

The respiratory health risks of this process are not known. Information on toxicologic aspects is available for some of the potential exposures. Titanium metal is believed to be biologically inert (2), but there are no reports on the pulmonary response to the inhalation of titanium particulates. Titanium dioxide given to rats by inhalation results in small subpleural deposits of the dust and focal areas of emphysema around the dust aggregates (3). Inhalation studies with rab-

\footnotetext{
1 Division of Occupational Health, University of Southern California School of Medicine, Los Angeles, California 90033, United States.

2 University of Michigan School of Public Health, Ann Arbor, Michigan 48109, United States.

3 Medical Services (Pulmonary Unit), Massachusetts General Hospital, Boston, Massachusetts 02114, United States.
}

Reprint requests to: Dr DH Garabrant, Division of Occupational Health, Department of Preventive Medicine, University of Southern California School of Medicine, 1420 San Pablo, B-306, Los Angeles, CA 90033, USA. bits have demonstrated decreases in pulmonary function accompanied by thickening of the alveolar septae (1). Pathological study of lung specimens from humans who have been heavily exposed to titanium dioxide has shown that the dust accumulates in the alveolar epithelium and on the surface of the lung and that subpleural fibrosis occurs (4). The severity of this reaction appears to be slight. Titanium tetrachloride is an extremely hazardous material which reacts violently with water to liberate heat and produce hydrochloric acid and titanium dioxide. Repeated exposures of dogs to titanium tetrachloride vapor at an average concentration of $8.4 \mathrm{ppm}$ produced pulmonary reactions similar to those produced by silica; the reactions were characterized by a reduced pulmonary ventilation capacity and proliferation of connective tissue (14). Acute inhalation produces intense chemical bronchitis and pneumonitis (8) and diffuse endobronchial polyposis (12).

We conducted the present cross-sectional investigation to determine whether there was evidence of respiratory disease among a cohort of titanium production workers. In the plant studied, there were separate areas for the reduction process and the chipping and washing process. Workers rotated job assignments within these areas but did not rotate between them. Maintenance and service personnel worked throughout the plant. Because of these work patterns it was possible to define three exposure groups.

\section{Subjects and methods}

\section{Subjects and survey procedures}

All 209 employees who were present in the plant during the two-week study period participated in the study. 
Forty-five employees who were absent from work because of vacation or illness during the study period were not included. The examination of each subject included the administration of a health questionnaire, a physical examination, pulmonary function testing, and chest radiography.

The questionnaire of the American Thoracic Society Epidemiology Standardization Project (5) was administered by interview to assess the prevalence of chronic respiratory symptoms, past medical history, and smoking history. A complete occupational history was also obtained. We determined previous asbestos exposure by asking each subject if he/she had ever engaged in occupations in which asbestos was used and by asking specifically about work in occupations with likely asbestos exposure. Each participant underwent a physical examination by a physician to determine the presence of adventitious chest sounds and finger clubbing. In addition, each subject was instructed to take a deep breath and cough hard; the examining physician judged the cough to be loose (productive) or dry (unproductive) by its sound, using the method of Gandevia (6).

In the determination of the exposure group to which each participant belonged, the company work records were abstracted for job title and dates of service. Three exposure groups were defined. Reduction workers were defined as those who had spent at least six months in the reduction area. Chipping and washing workers were defined as those who had spent at least six months in the chipping and washing area but who had spent less than six months in the reduction area. Maintenance and service workers were defined as those who had spent less than six months in production jobs (reduction or chipping and washing). Maintenance and service workers performed repair jobs in each production area, but the time spent in each area was considerably less than that of the production workers who were assigned there full time.

A single $14 \times 17$-inch $(35.6 \times 43.2-\mathrm{cm})$ posteroanterior chest radiograph was obtained for each subject. Radiographs were read by a certified " $B$ " reader of the National Institute for Occupational Safety and Health (NIOSH) according to the criteria of the International Labour Office (ILO) (7). They were read without knowledge of the subject's age, exposure history, or other information.

Spirometry was performed in the plant by trained technicians using a Stead-Wells spirometer, according to the recommended standard procedures for pulmonary function testing of the American Thoracic Society (5). The spirometer was calibrated and checked for leaks at the start of each session. The technicians were unaware of the subjects' exposure histories. Each subject completed a minimum of three acceptable forced expiratory maneuvers. The maximum value of the forced expiratory volume in $1 \mathrm{~s}\left(\mathrm{FEV}_{1.0}\right)$ was read from the spirograms and used as the index of ventilatory capacity in the analysis, after adjustment to body temperature and ambient pressure saturated with water vapor.

\section{Statistical analysis}

Respiratory symptoms, objective cough, adventitious chest sounds, and finger clubbing were analyzed in comparisons of the prevalence of each finding among the three exposure groups. Fisher's exact test (13) was used to determine whether the prevalence in each group differed from that in the other groups.

For the purpose of analysis, cough was defined as a usual cough as much as four to six times a day, four or more days of the week for three consecutive months or more during the year. Phlegm was defined as usual phlegm as much as twice a day four or more days of the week for three consecutive months or more during the year. Chronic bronchitis was defined with the same criteria as phlegm but with a duration of at least two years. Wheezing with dyspnea was defined as ever having an attack of wheezing accompanied by shortness of breath. Dyspnea on exertion was defined as having to walk slower than people of the same age on a level surface because of breathlessness, or worse.

Stepwise multiple regression techniques were used to analyze the relationship between the $\mathrm{FEV}_{1.0}$ and the height, age, duration of smoking, pack-years of cigarette smoking, and the duration of time worked in each exposure area. These procedures were performed with the SPSS batch system (11).

Abnormalities in the chest radiographs were analyzed in relation to the duration of employment and in relation to past asbestos exposure by means of contingency tables. Rate ratios were calculated, and significance testing was performed with Fisher's exact test (13). Multiple logistic regression models were also used to assess the effects of asbestos exposure, smoking, age, and work in the titanium industry on the presence or absence of pleural thickening with the use of the GLIM system (10).

\section{Results}

The three exposure groups were comparable in terms of the number of years they had been employed in titanium manufacturing, education, height, race, and sex. The maintenance workers were slightly older and had smoked longer than the other two groups. The mean ages of the three groups were: maintenance workers, 42.3 years; chipping and washing workers, 35.0 years; and titanium tetrachloride reduction workers, 34.5 years. The mean durations of cigarette smoking for the three groups were: maintenance workers, 16.5 years; chipping and washing workers, 10.9 years; and titanium tetrachloride reduction workers, 11.0 years. 
Table 1. Prevalence of respiratory symptoms and abnormal physical findings according to exposure group.

\begin{tabular}{|c|c|c|c|}
\hline & \multicolumn{3}{|c|}{ Exposure group } \\
\hline & \multicolumn{2}{|c|}{ Production workers } & \multirow[b]{2}{*}{$\begin{array}{c}\text { Maintenance and serv- } \\
\text { ice workers }(\mathrm{N}=58) \\
\text { percent affected }\end{array}$} \\
\hline & $\begin{array}{c}\text { Reduction workers } \\
(\mathbf{N}=78), \text { percent } \\
\text { affected }\end{array}$ & $\begin{array}{l}\text { Chipping and washing } \\
\text { workers }(N=73) \\
\text { percent affected }\end{array}$ & \\
\hline \multicolumn{4}{|l|}{ Symptoms } \\
\hline $\begin{array}{l}\text { Cough } \\
\text { Phlegm } \\
\text { Chronic bronchitis } \\
\text { Wheezing with dyspnea } \\
\text { Dyspnea on exertion }\end{array}$ & $\begin{array}{r}5 \\
14 \\
9 \\
14 \\
0\end{array}$ & $\begin{array}{r}14 \\
16 \\
11 \\
21 \\
1\end{array}$ & $\begin{array}{r}5 \\
9 \\
3 \\
12 \\
3\end{array}$ \\
\hline \multicolumn{4}{|l|}{ Physical findings } \\
\hline $\begin{array}{l}\text { Abnormal breath sounds } \\
\text { Rales } \\
\text { Loose (productive) cough } \\
\text { Finger clubbing }\end{array}$ & $\begin{array}{l}3 \\
3 \\
1\end{array}$ & $\begin{array}{r}12 \\
3 \\
5\end{array}$ & $\begin{array}{r}10 \\
2 \\
0\end{array}$ \\
\hline
\end{tabular}

a Prevalence significantly higher among chipping and washing workers than among reduction workers, $p=0.02$.

\section{Symptoms}

The prevalences of cough, phlegm production, chronic bronchitis, and wheezing with dyspnea were the highest among the chipping and washing workers, intermediate among the reduction workers, and lowest among the maintenance workers (table 1). There was no significant difference in the prevalence of symptoms between the groups. Rales were significantly more common among the chipping and washing workers than among the reduction workers.

\section{Pulmonary function tests}

A regression analysis of the $\mathrm{FEV}_{1.0}$ data demonstrated that age, height, and the total years of cigarette smoking were significantly related to this measure of pulmonary function (table 2). After adjustment for these variables, the number of years worked in the reduction area was related to a reduction of $24 \mathrm{ml}$ per year.

\section{Chest radiographs}

Small irregular opacities of profusion $1 / 0$ were present in the radiographs of nine subjects (eight of these were type t). The prevalence was $3 \%$ among the reduction workers (two cases), $4 \%$ among the chipping and washing workers (three cases), and $7 \%$ among the maintenance workers (four cases). Small round opacities of profusion 1/0 were present in the radiographs of only three subjects (one chipping and washing worker and two maintenance and service workers). There were no radiographs in which the profusion of opacities exceeded $1 / 0$.

Pleural disease, including pleural plaques and diffuse pleural thickening, was present in the radiographs of 36 subjects. The prevalence was $10 \%$ among the reduction workers (eight cases), $22 \%$ among the chipping and washing workers (16 cases), and $21 \%$ among the maintenance and service workers (12 cases).
Table 2. Linear regression equation for the measurements of forced expiratory volume in $1 \mathrm{~s}$ in relation to exposure among white males $\geq 25$ years of age $(\mathrm{N}=163)$.

\begin{tabular}{|c|c|c|c|}
\hline Variate & Coefficient & $\begin{array}{l}\text { Standard } \\
\text { error of the } \\
\text { coefficient }\end{array}$ & $p$-Value \\
\hline \multirow{3}{*}{$\begin{array}{l}\text { Age (years) } \\
\text { Height (cm) } \\
\text { Years smoked } \\
\text { cigarettes } \\
\text { Years worked } \\
\text { in reduction }\end{array}$} & $\begin{array}{l}-0.032 \\
+0.037\end{array}$ & $\begin{array}{l}0.0038 \\
0.0056\end{array}$ & $\begin{array}{l}0.0001 \\
0.0001\end{array}$ \\
\hline & -0.012 & 0.0032 & 0.0004 \\
\hline & -0.024 & 0.013 & 0.07 \\
\hline $\begin{array}{l}\text { Intercept } \\
\text { Multiple correla }\end{array}$ & \multicolumn{2}{|c|}{$\begin{array}{l}-1.582 \\
\text { ient: } R^{2}=0.54\end{array}$} & . \\
\hline
\end{tabular}

Pleural disease was strongly associated with the duration of work in titanium manufacturing (table 3 ) and was also associated with previous asbestos exposure. Among those workers who had no previous asbestos exposure, the risk of pleural disease for those who had been employed for at least 10 years in titanium manufacturing was 3.8 times that for workers who had been employed for less than five years.

Logistic regression also showed that pleural thickening was strongly related to the duration of work in titanium manufacturing $(p<0.001)$. After allowance for the effect of work in titanium manufacturing, previous asbestos exposure was not significantly related to pleural thickening ( $p=0.12$ ), nor was cigarette smoking $(\mathrm{p}=0.18)$.

\section{Pleural thickening in relation to pulmonary function, symptoms and findings from the physical examination}

There were no significant differences in pulmonary function, symptom prevalence, abnormalities revealed in the physical examination, or pulmonary function between the subjects who had pleural thickening and those who did not. 
Table 3. Pleural thickening according to duration of work in titanium manufacturing and according to past asbestos exposure.

\begin{tabular}{|c|c|c|c|c|}
\hline \multirow{2}{*}{ Exposure } & \multicolumn{2}{|c|}{ Pleural thickening } & \multirow{2}{*}{ Rate ratio } & \multirow{2}{*}{ p-Value } \\
\hline & Present & Absent & & \\
\hline \multicolumn{5}{|c|}{ Duration of work in titanium manufacturing } \\
\hline$<5$ years & 7 & 77 & 1.0 & $\cdot$ \\
\hline 5 to 9 years & 5 & 43 & 1.3 & 0.44 \\
\hline$\geq 10$ years & 24 & 53 & 3.7 & 0.0002 \\
\hline Total & 36 & 173 & $\cdot$ & $\cdot$ \\
\hline \multicolumn{5}{|l|}{ Past asbestos exposure } \\
\hline No & 32 & 165 & 1.0 & $\cdot$ \\
\hline Yes & 4 & 8 & 2.1 & 0.13 \\
\hline Total & 36 & 173 & & \\
\hline \multicolumn{5}{|c|}{$\begin{array}{l}\text { Duration of work in titanium manufacturing } \\
\text { by past asbestos exposure }\end{array}$} \\
\hline \multicolumn{5}{|c|}{ Never exposed to asbestos } \\
\hline $\begin{array}{l}<5 \text { years of work in titanium } \\
\text { manufacturing }\end{array}$ & 6 & 70 & 1.0 & - \\
\hline $\begin{array}{l}5 \text { to } 9 \text { years of work in } \\
\text { titanium manufacturing }\end{array}$ & 4 & 43 & 1.1 & 0.58 \\
\hline $\begin{array}{l}\geq 10 \text { years of work in } \\
\text { titanium manufacturing }\end{array}$ & 22 & 52 & 3.8 & 0.0005 \\
\hline \multicolumn{5}{|l|}{ Exposed to asbestos } \\
\hline $\begin{array}{l}<5 \text { years of work in titanium } \\
\text { manufacturing }\end{array}$ & 1 & 7 & 1.6 & 0.52 \\
\hline $\begin{array}{l}5 \text { to } 9 \text { years of work in } \\
\text { titanium manufacturing }\end{array}$ & 1 & - & 12.7 & 0.09 \\
\hline $\begin{array}{l}\geq 10 \text { years of work in titanium } \\
\text { manufacturing }\end{array}$ & 2 & 1 & 8.4 & 0.03 \\
\hline
\end{tabular}

\section{Discussion}

Our choice of maintenance and service workers as a comparison group for production workers in the assessment of respiratory symptoms and pleural disease probably led to an underestimation of any true association which existed. The maintenance and service workers had a higher prevalence of cigarette smoking and also had a higher prevalence of past asbestos exposure than the reduction workers. These factors may have increased their prevalence of respiratory symptoms and chest radiograph abnormalities and may have adversely affected their pulmonary function.

The etiology of the reduced ventilatory capacity is unclear from the information available. An industrial hygiene survey carried out in the plant by NIOSH during this investigation indicated that exposures to hydrochloric acid were negligible and that there was no measurable exposure to volatile organics or asbestos. Total particulates, consisting primarily of titanium dioxide, ranged from 0.2 to $2.8 \mathrm{mg} / \mathrm{m}^{3}$ in the reduction area.

Titanium tetrachloride, which is used in the reduction area, was not measured. This material probably represents the greatest acute hazard in the plant when it is inadvertantly released into the air. It spontaneously combines with water vapor to produce a dense cloud of titanium dioxide, hydrochloric acid, and titanium oxychloride. Experiments with dogs in repeated exposures have shown that it causes a reduction in pulmonary capacity and proliferation of connective tissue (14).

Although no asbestos was detected in the air at the time of the survey by NIOSH, asbestos had been used in the past in heat shielding drapes in the reduction area and in insulation for pipes throughout the plant. We presume that asbestos exposure may have contributed to the pleural thickening in some of the subjects, particularly in the maintenance workers who were responsible for pipefitting and maintaining the reduction furnaces. No measurements of past asbestos exposure in the plant were available, so it is unclear whether or not asbestos exposure could explain the pattern of pleural thickening seen among the workers. The observation that pleural thickening was more common among the chipping and washing workers is difficult to explain on the basis of asbestos exposure, as work in the chipping and washing area did not apparently involve exposure to asbestos, whereas maintenance workers and reduction workers maintained and operated asbestos-insulated equipment. The pleural thickening of the chipping and washing workers was less extensive in terms of its thickness and length along the lateral chest wall than that of the maintenance workers. These observations are consistent with the hypothesis that an agent other than asbestos also contributed to the development of pleural thickening.

There are indications that the inhalation of titanium dioxide by humans may cause localized increases in 
connective tissue in the lungs (4) and titanium dioxide to accumulate in patches on the lung surface (9). Similar findings among rats also suggest that pleural changes may occur in response to the inhalation of titanium dioxide (3). Our data are consistent with the hypothesis that titanium dioxide may contribute to the development of pleural thickening, but they are not conclusive because of the limited information available regarding past asbestos exposure in the plant.

Our data do not show a clear association between pleural thickening and a reduction in ventilatory capacity, and therefore these abnormalities may not be related to a common exposure. Reductions in the $\mathrm{FEV}_{1.0}$ in relation to work in the reduction area and pleural thickening among the chipping and washing and maintenance workers support this view. This issue needs clarification.

\section{Acknowledgments}

We thank Ms L Pothier and Ms J Held for their statistical assistance, Ms J Howland and Ms C Cedillo for typing the manuscript, and $\mathrm{Mr} \mathrm{C}$ Moseley who was the NIOSH Project Officer.

\section{References}

1. American Conference of Governmental Industrial Hygienists. Documentation of the threshold limit values. Fourth edition. Cincinnati, OH 1980, pp 399-400.

2. Browning E. Toxicity of industrial metals. Second edition. Butterworths, London 1969, p 332.

3. Christie H, Mackay RJ, Fisher AM. Pulmonary effects of inhalation of titanium dioxide by rats. Am Ind Hyg Assoc J 24 (1963) 42-46.

4. Elo R, Maatta K, Uksila E, Arstila AU. Pulmonary deposits of titanium dioxide in man. Arch Pathol 94 (1972) 417-424.

5. Ferris BG. Epidemiology standardization project. Am Rev Respir Dis 118 (1978) 7-35 \& 55-88.

6. Gandevia BH. Clinical techniques. In: Weill $\mathrm{H}$, TurnerWarwick M, ed. Occupational lung diseases, research approaches and methods. Marcel Dekker, New York, NY 1981, pp $11-33$.

7. International Labour Office. Guidelines for the use of ILO international classification of radiographs of pneumoconoises. Revised edition. Geneva 1980. (Occupational safety and health series no 22).

8. Lawson JJ. The toxicity of titanium tetrachloride. J Occup Med 3 (1961) 7-12.

9. Maatta K, Arstila AU. Pulmonary deposits of titanium dioxide in cytologic and lung biopsy specimens. Lab Invest 33 (1975) $342-346$.

10. Nelder JA. GLIM manual, release 2: General linear interactive modelling. Numerical Algorithms Group, Oxford 1975 .

11. Nie NH, Hull CH. SPSS II: Preliminary manual. Statistical Package for the Social Sciences, Inc, Chicago, IL 1980.

12. Park T, DiBenedetto R, Morgan K, Colmers R, Sherman E. Diffuse endobronchial polyposis following a titanium tetrachloride inhalation injury. Am Rev Respir Dis 130 (1984) $315-317$.

13. Rothman KJ, Boice JD. Epidemiologic analysis with a programmable calculator. US Department of Health, Education, and Welfare, Washington, DC 1979, pp $25-32$. (NIH publication no $79-1649$ ).

14. Stokinger HE. The metals. In: Clayton GD, Clayton FE, ed. Patty's industrial hygiene and toxicology. Volume IIA. Third edition. Wiley-Interscience, New York, NY 1981, pp 1968-1981.

Received for publication: 23 June 1986 